\title{
Psoriasis and cardiovascular diseases: Current developments in medical research
}

\author{
Psoriazisul şi bolile cardiovasculare: Actualităţi în cercetarea medicală
}

\author{
Ana Maria Alexandra Stănescu, Camelia Diaconu, Mihaela Adela lancu, \\ Gabriel Cristian Bejan, Constantin Ştefani, Ioana Veronica Grăjdeanu \\ Universitatea de Medicină şi Farmacie „Carol Davila“, Bucureşti,România
}

\begin{abstract}
Patients with psoriasis are prone to develop cardiovascular disease, being one of the main causes of mortality. Risk factors for patients with psoriasis for cardiovascular disease are very common either on their own or in combination. Among these risk factors we can mention: diabetes, obesity, hypertension, dyslipidemia, metabolic syndrome, smoking. The presence of arthritis along with psoriasis is a negative prognosis in terms of cardiovascular disease. Sleep disturbances, depression and anxiety disorders also contribute to the in-crease in the frequency of cardiovascular disease in patients with psoriasis.
\end{abstract}

Keywords: psoriasis, cardiovascular diseases, myocardial infarction, stroke, metabolic syndrome, obesity

\begin{abstract}
Pacienţii cu psoriazis sunt predispuşi în a dezvolta boli cardiovasculare, fiind una dintre principalele cauze de mortalitate ale acestora. Factorii de risc ai pacienţilor cu psoriazis pentru bolile cardiovasculare sunt foarte des întâlniţi fie de sine stătători, fie în asociere. Dintre aceşti factori de risc, putem menţiona: diabetul, obezitatea, hipertensiunea arterială, dislipidemia, sindromul metabolic. Prezenţa artritei alături de psoriazis reprezintă, de asemenea, un prognostic negativ din punct de vedere al bolilor cardiovasculare. Fumatul, tulburările de somn, depresia şi tulburările de anxietate contribuie şi ele la creşterea frecvenţei bolilor cardiovasculare la pacienţii cu psoriazis.
\end{abstract}

Cuvinte cheie: psoriazis, boli cardiovasculare, infarct miocardic, accident vascular cerebral, sindrom metabolic, obezitate

\section{INTRODUCERE}

Psoriazisul nu mai este o necunoscută; este o boală intens studiată la nivel mondial, fiind foarte clar faptul că psoriazisul nu poate fi considerat o simplă boală dermatologică, ci abordarea trebuie făcută din punct de vedere multidisciplinar $(1,2)$.

Reprezintă o boală cronică, inflamatorie (3), caracterizată nu numai prin afectare cutanată, ci şi prin cea sistemică, cu o varietate de morbidităţi asociate (4).
Studiile epidemiologice sugerează că morbiditatea şi mortalitatea la pacienţii cu psoriazis se datorează în principal bolilor cardiovasculare $(\mathrm{CV})$, incluzând infarctul miocardic (MI), accidentul vascular cerebral şi boala arterială periferică $(5,6)$.

În plus, formele de psoriazis uşor şi sever sunt asociate cu o incidenţă mai mare a factorilor de risc $\mathrm{CV}$, precum hipertensiunea, diabetul zaharat, obezitatea şi sindromul metabolic, contribuind în continuare la creşterea riscului $\mathrm{CV}$ al acestor pacienţi (7). 


\section{Cercetare de actualitate a relaţiei psoriazis - boală cardiovasculară}

În urma meta-analizei a 13 studii observaţionale, pacienţii cu psoriazis uşor au avut un risc crescut de accident vascular cerebral [Rata de risc (HR) $=1,10$, CI 95\%: 1,0-1,19] şi infarct miocardic (MI $=\mathrm{HR}=1,20$, CI 95: 1,06-1,35). Riscul de AVC $(\mathrm{HR}$ $=1,38$, CI 95\%: 1,20-1,60), IM $(\mathrm{HR}=1,70, \mathrm{CI}$ 95\%: $1,18-2,43)$ şi deces cardiovascular $(\mathrm{HR}=$ 1,37, 95\% CI: $1,13-1,67)$ este crescut la pacienţii cu psoriazis sever (8).

Dintre cele 2,7 milioane de persoane, dintre care 300.000 de pacienţi cu psoriazis, raportul de risc pentru hipertensiune arterială la pacienţii cu psoriazis a fost 1,58 (intervalul de încredere 95\% [CI]: 1,42-1,76) comparativ cu martorii; pacienţii cu artrită psoriazică au avut o prevalenţă şi mai mare a hipertensiunii arteriale (OR: 2,07; CI 95\%: 1,41$3,04)(9)$.

S-a constatat că pacienţii cu psoriazis au o inflamaţie vasculară aortică mai mare şi există o asociere între severitatea psoriazisului şi gradul inflamaţiei vasculare. O dată cu ameliorarea cutanată a psoriazisului se poate ajunge la o reducere a inflamaţiei vasculare aortice $(10,11)$.

\section{Corelaţii între psoriazis şi factorii de risc cardiovasculari}

\section{Hipertensiunea arterială}

Pacienţii cu psoriazis sunt mai puţin susceptibili de a realiza controlul tensiunii arteriale în timpul tratamentului antihipertensiv şi pot necesita utilizarea mai multor medicamente antihipertensive comparativ cu pacienţii nonpsoriatici $(13,14)$.

Într-un studiu care a implicat 77.728 de femei, s-a constatat că pacientele cu hipertensiune ar avea un risc mai mare de apariţie a psoriazisului (15).

\section{Sindromul metabolic}

Din cauza creşterii obezităţii la nivel mondial, creşte şi incidenţa sindromului metabolic $(16,17)$; pe lângă obezitate, şi restul componentelor sindromului metabolic sunt în creştere, îndeosebi la pacienţii cu psoriazis. Pacienţii cu psoriazis sunt predispuşi de a dezvolta sindrom metabolic, ceea ce poate duce la predispoziţia de a dezvolta boli cardiovasculare.

\section{Diabet}

Datele colectate din 27 de studii observaţionale $\mathrm{au}$ asociat, de asemenea, coexistenţa diabetului $\mathrm{cu}$ psoriazis (OR 1/4 1,59; CI 95\%: 1,38-1,83 pentru diabet la pacienţii cu psoriazis). Severitatea psoriazi-

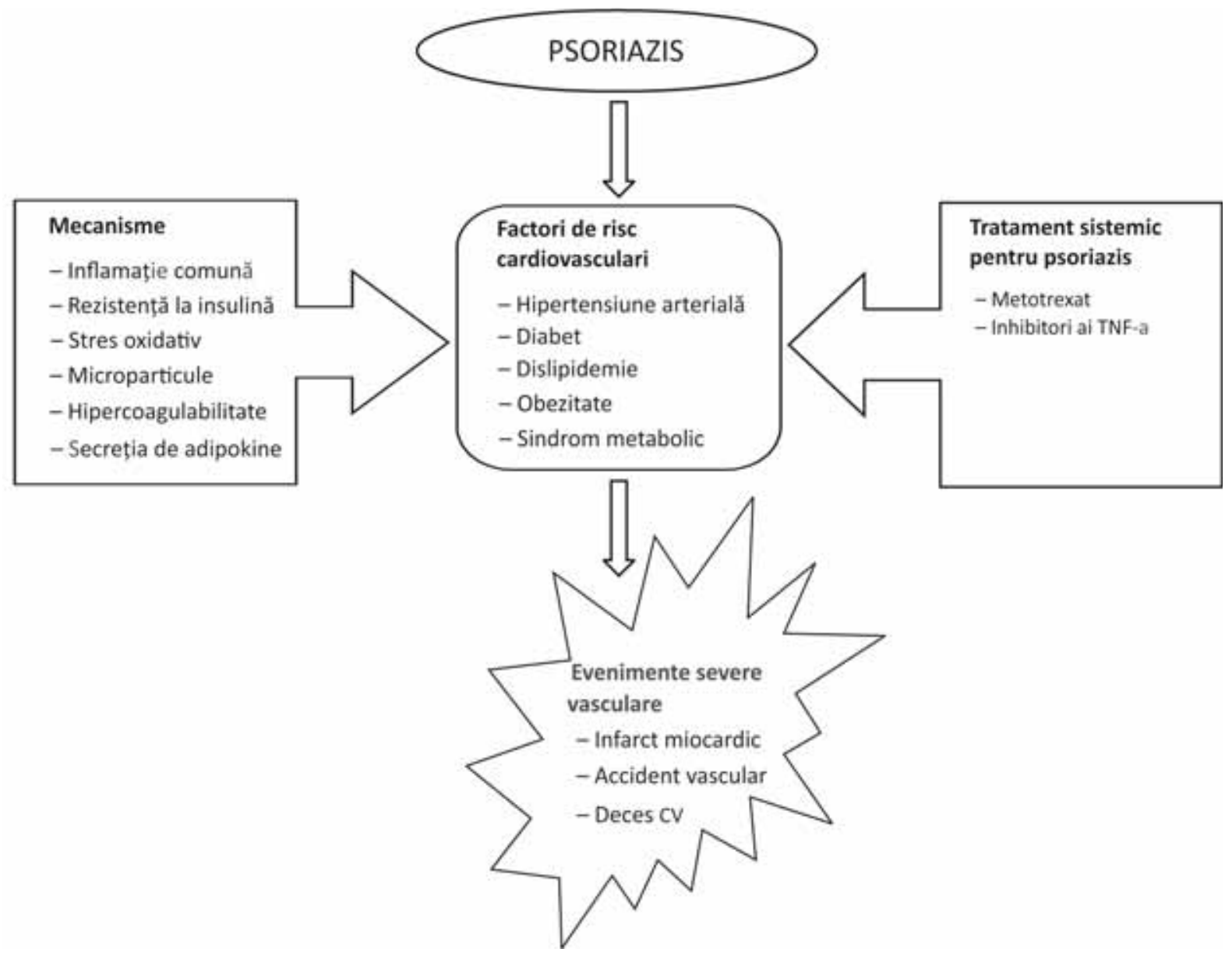

FIGURA 1. Mecanismele prin care psoriazisul influențează producerea bolilor cardiovasculare (12) 
sului a fost asociată pozitiv cu prevalenţa diabetului (OR: 1,53 şi 1,97; CI 95\%: 1,16-2,04 şi 1,48-2,62; pentru pacienţii cu psoriazis uşor şi sever) (18).

În cadrul unui studiu de cohortă pe populaţia din Taiwan, s-a constatat că psoriazisul este asociat cu dezvoltarea diabetului zaharat şi riscul este mai mare cu cât psoriazisul este mai sever. De asemenea, pacienţii cu psoriazis au o rezistenţă crescută la insulină comparativ cu populaţia fără psoriazis, ceea ce sugerează că psoriazisul poate fi o tulburare prediabetică $(19,20)$.

Pacienţii care au concomitent diabet zaharat şi psoriazis prezintă un risc mai mare de a dezvolta complicaţii microvasculare şi macrovasculare, comparativ cu pacienţii diabetici fără psoriazis (21).

\section{Dislipidemie}

Dislipidemia este des întâlnită la pacienţii cu psoriazis, fiind asociat cu HDL scăzut şi LDL crescut; de asemenea, s-au înregistrat creşteri ale trigliceridelor (22). Mai multe studii sunt necesare pentru a determina exact relaţia psoriazis - dislipidemie - boală cardiovasculară.

Obezitate

Este binecunoscută asocierea psoriazisului cu obezitatea, scăderea în greutate ducând la ameliorarea manifestărilor psoriazisului.

Este posibil ca obezitatea să fie o consecinţă a psoriazisului şi nu un factor de risc (23).

Diferite studii au arătat că producţia dezordonată de adipokine din ţesutul gras la pacienţii obezi cu psoriazis poate duce la inflamaţii cronice ale pielii, sistemice şi la un risc crescut cardiovascular (24).

Alți factori care cresc riscul de boală cardiovasculară la pacienții cu psoriazis - fumatul, tulburările de somn, depresiile, tulburările de anxietate, artrita

Meta-analiza a 25 de studii observaţionale pe 150.000 de pacienţi cu psoriazis şi mai mult de o jumătate de milion de pacienţi fără psoriazis a arătat o asociere între psoriazis şi fumători (OR: 1,78; 95\% CI: 1,52-2,06), dar şi între psoriazis şi foşti fumători (OR: 1,62; 95\% CI: 1,33-1,99). În plus, s-a observat o asociere între fumat şi incidenţa psoriazisului, asociere proporţională cu durata şi intensitatea fumatului (25).

Un studiu de cohortă din Taiwan a constatat că riscul de boală cardiacă ischemică și accident vascular cerebral este mai mare la pacienţii cu psoriazis care prezintă tulburări de somn comparativ cu pacienţii cu psoriazis care nu au aceste tulburări (26).
Prezenţa depresiei este foarte des întâlnită la pacienţii cu psoriazis, aceasta numărându-se, de asemenea, printre factorii favorizanţi ai bolilor cardiovasculare.

Rezultatele altui studiu au arătat că prevalenţa tulburării de anxietate este mai mare la pacienţii cu psoriazis în comparaţie cu lotul control (pacienţi fără psoriazis), iar pacienţii cu psoriazis cu anxietate prezintă un risc mai mare de a dezvolta boala cerebrovasculară în comparaţie cu pacienţii cu psoriazis fără anxietate (raportul de risc 1,37) (27).

S-a constatat că pacienţii cu psoriazis şi artrită au avut un risc mai mare de a dezvolta evenimente vasculare grave (raportul de risc 1,46 pentru bolile cardiovasculare şi 1,82 pentru boala cerebrovasculară), comparativ cu pacienţii cu psoriazis fără artrită (28).

Mecanismele patogene prin care relaţionează psoriazisul cu boala cardiovasculară sunt: factori genetici comuni, căi comune inflamatorii, adipokine proinflamatorii, rezistenţa la insulină, funcţia şi compoziţia lipoproteinelor, angiogeneza şi stresul oxidativ, hipercoagulabilitatea, nivelul homocisteinei serice.

Riscul crescut de boli CV al pacienţilor cu psoriazis poate fi atribuit căilor patofiziologice comune care stau la baza atât a psoriazisului, cât şi a aterosclerozei. Prezenţa concomitentă a altor factori de risc $\mathrm{CV}$ agravează semnificativ profilul $\mathrm{CV}$ al pacienţilor cu psoriazis (29).

Speranţa de viaţă a pacienţilor cu psoriazis moderat până la sever este scăzută cu aproximativ 5 ani, în principal din cauza comorbidităţilor cardiovasculare (30).

\section{CONCLUZII}

În concluzie, psoriazisul se asociază cu un risc crescut de a dezvolta boli cardiovasculare, în special infarct miocardic şi accident vascular cerebral.

$\mathrm{Cu}$ cât este mai mare severitatea psoriazisului, cu atât creşte şi riscul de a dezvolta boli cardiovasculare.

O multitudine de factori influenţează apariţia bolilor cardiovasculare la pacienţii cu psoriazis.

În consecinţă, deşi rareori psoriazisul duce la mortalitate, prin incidenţa mare a comorbidităţilor, rata de mortalitate la aceşti pacienţi a crescut mult faţă de populaţia generală.

Conflict of interest: none declared Financial support: none declared 


\section{BIBLIOGRAFIE}

1. Stănescu Ana Maria Alexandra, loana Veronica Grăjdeanu, Ekua Asafoaba Appiah, Gabriel Cristian Bejan, Mihaela Adela lancu, Călin Giurcăneanu. Abordare diferenţiată a psoriazisului în funcţie de vârsta pacientului. Practica Medicală. 2017; 12, 4(53): 204-207.

2. Stănescu Ana Maria Alexandra, Matei A., Grăjdeanu I.V. et al. Multipli factori de interes în managementul psoriazisului şi comorbidităţilor asociate. Practica Medicală. 2016; 11: 49-52. http:// rjmp.com.ro/multipli-factori-de-interes-in-managementul-psoriazisuluisi-comorbiditatilor-asociate/

3. Stănescu A.M.A. Psoriazisul. În: Dumitru M. Esenţialul în medicina de familie, ediţia 3. Amaltea, Bucureşti 2016: 384-388.

4. Stănescu Ana Maria Alexandra, Alexandru Matei, loana Veronica Grăjdeanu, Ekua Asafoaba Appiah, Cristi Paparău, Călin Giurcăneanu. Asocierea între psoriazis şi sindromul metabolic, corelată cu deficitul vitaminei D în ambele afecţiuni. Revista Medicală Română 2016; 1: 81-85

5. Mosca S., Gargiulo P., Balato N. et al. Ischemic cardiovascular involvement in psoriasis: a systematic review. Int J Cardiol. 2015; 178:191-199.

6. Katsiki N., Anagnostis P., Athyros V.G., Karagiannis A., Mikhailidis D.P. Psoriasis and vascular risk: An update. Curr Pharm Des. 2014; 20(39):6114-6125.

7. Henseler T., Christophers E. Disease concomitance in psoriasis. J Am Acad Dermatol. 1995; 32(6):982-986.

8. Raaby L., Ahlehoff O., de Thurah A. Psoriasis and cardiovascular events: Updating the evidence. Arch Dermatol Res (2017) 309: 225. https://doi-org.ezproxy.umf.ro/10.1007/s00403-016-1712-1

9. Armstrong A.W., Harskamp C.T., Armstrong E.J. The association between psoriasis and hypertension: a systematic review and meta-analysis of observational studies. J Hypertens. 2013; 31(3): 433-442.

10. Naik H.B., Natarajan B., Stansky E., Ahlman M.A., Teague H., Salahuddin T., Ng Q., Joshi A.A., Krishnamoorthy P., Dave J. et al. Severity of psoriasis associates with aortic vascular inflammation detected by FDG PET/CT and neutrophil activation in a prospective observational study. Arterioscler. Thromb. Vasc. Biol. 2015, 35, 2667-2676.

11. Dey A.K., Joshi A.A., Chaturvedi A., Lerman J.B., Aberra T.M., Rodante J.A. et al. Association between skin and aortic vascular inflammation in patients with psoriasis: A case-cohort study using positron emission tomography/computed tomography. JAMA Cardiol. 2017, 2, 1013-1018.

12. Hu, Stephen. Psoriasis and Cardiovascular Comorbidities: Focusing on Severe Vascular Events, Cardiovascular Risk Factors and Implications for Treatment. International journal of molecular sciences. 2017; 18(10): 2211. doi:10.3390/ijms18102211

13. Takeshita J., Wang S., Shin D.B. et al. Effect of psoriasis severity on hypertension control: a population-based study in the United Kingdom. JAMA Dermatol. 2015; 151(2):161-169.

14. Armstrong A.W., Lin S.W., Chambers C.J., Sockolov M.E., Chin D.L. Psoriasis and hypertension severity: results from a case-control study. PLoS One. 2011; 6(3):e18227.

15. Wu S., Han J., Li W.Q., Qureshi A.A. Hypertension, antihypertensive medication use, and risk of psoriasis. JAMA Dermatol. 2014, 150, 957-963.

16. Stănescu Ana Maria Alexandra, loana Veronica Grăjdeanu, Gabriel Cristian Bejan, Mihaela Adela lancu, Ekua Asafoaba
Appiah, Răzvan Peagu. Sindromul metabolic în raport cu nivelul seric al vitaminei D corelat cu afectarea cutanată. Revista Medicală Română. 2017; 4: 300-304. https://view.publitas.com/amph/ rmj_2017_4_art-08/page/5

17. Stănescu Ana Maria Alexandra, Ana Maria Goanţă, Roxana Ignătescu, Ekua Asafoaba Appiah, Ioana Veronica Grăjdeanu, Lucian Ioniţă. Aspecte comparative la om şi animal în diagnosticul sindromului metabolic şi disfunctiei metabolice asociate obezităţii. Practica Medicală 2017; 12, 4(53): 250-255

18. Armstrong A.W., Harskamp C.T., Armstrong E.J. Psoriasis and the risk of diabetes mellitus: a systematic review and meta-analysis. JAMA Dermatol. 2013;149(1):84-91.

19. Lee M.S., Lin R.Y., Lai M.S. Increased risk of diabetes mellitus in relation to the severity of psoriasis, concomitant medication and comorbidity: A nationwide population-based cohort study. J. Am. Acad. Dermatol. 2014, 70, 691-698.

20. Gyldenlove M., Storgaard H., Holst J.J., Vilsboll T., Knop F.K., Skov L. Patients with psoriasis are insulin resistant. J. Am. Acad. Dermatol. 2015, 72, 599-605.

21. Armstrong A.W., Guerin A., Sundaram M., Wu E.Q., Faust E.S., Ionescu-Ittu R., Mulani P. Psoriasis and risk of diabetes-associated microvascular and macrovascular complications. J. Am. Acad. Dermatol. 2015, 72, 968-977.

22. Ma C., Harskamp C.T., Armstrong E.J., Armstrong A.W. The association between psoriasis and dyslipidaemia: A systematic review. Br. J. Dermatol.

23. Herron M.D., Hinckley M., Hoffman M.S., Papenfuss J., Hansen C.B., Callis K.P., Krueger G.G. Impact of obesity and smoking on psoriasis presentation and management. Arch. Dermatol. 2005, 141, 1527-1534.

24. Coimbra S., Catarino C., Santos-Silva A. The triad psoriasisobesity-adipokine profile. J. Eur. Acad. Dermatol. Venereol. JEADV 2016, 30, 1876-1885.

25. Armstrong A.W., Harskamp C.T., Dhillon J.S., Armstrong E.J. Psoriasis and smoking: A systematic review and meta-analysis. $\mathrm{Br} \mathrm{J}$ Dermatol. 2014; 170(2):304-314.

26. Chiu H.Y., Hsieh C.F., Chiang Y.T., Tsai Y.W., Huang W.F., Li C.Y., Wang T.S., Tsai T.F. Concomitant sleep disorders significantly increase the risk of cardiovascular disease in patients with psoriasis. PLOS ONE 2016, 11, e0146462.

27. Lan C.C., Yu H.S., Li W.C., Ko Y.C., Wu C.S., Lu Y.W., Yang Y.H., Chen G.S. Anxiety contributes to the development of cerebrovascular disease in Taiwanese patients with psoriasis: A population-based study. Eur. J. Dermatol. EJD 2013, 23, 290-292.

28. Chin Y.Y., Yu H.S., Li W.C., Ko Y.C., Chen G.S., Wu C.S., Lu Y.W., Yang Y.H., Lan C.C. Arthritis as an important determinant for psoriatic patients to develop severe vascular events in Taiwan: A nation-wide study. J. Eur. Acad. Dermatol. Venereol. JEADV 2013, 27, 1262-1268.

29. Michael Doumas, Niki Katsiki, Vasilios Papademetriou. Psoriasis and Cardiovascular Disease: Two Sides of the Same Coin? Angiology 2018; 69(1): 5-9. https://doi.org/10.1177/0003319717702303

30. Siegel D., Devaraj S., Mitra A., Raychaudhuri S.P., Raychaudhuri S.K., Jialal I. Inflammation, atherosclerosis and psoriasis. Clin. Rev. Allergy Immunol. 2013, 44, 194-204. 